\title{
THE ROLE OF EPOXIDATION ON CAMELINA Sativa BIODIESEL PROPERTIES
}

\author{
CIUBOTA-ROSIE C. \\ DÍAZ-MEDINO A. \\ RAMOS M.J. \\ A. PÉREZ* \\ M. CARMONA \\ J.F. RODRÍGUEZ
}

\author{
Institute of Chemical and Environmental Technologies \\ Department of Chemical Engineering \\ University of Castilla - La Mancha
}

Av. Camilo José Cela s/n, 13005 Ciudad Real, Spain

Received: 31/01/2013

Accepted: $27 / 03 / 2014$

*to whom all correspondence should be addressed:

Available online: 29/05/2014

e-mail: Angel.Perez@uclm.es

\section{ABSTRACT}

An unstandarised biodiesel made from Camelina sativa oil, having over a 90 percent by weight of unsaturated fatty acids, were transformed into an epoxidised biodiesel that satisfy the requirements for iodine value, linolenic acid methyl ester content, cetane number, polyunsaturated fatty acids content, and viscosity established by the EN 14214 and ASTM D 6751 standards. The epoxidation reaction was carried out at $60^{\circ} \mathrm{C}$ using peroxyacetic acid generated in situ and sulphuric acid as catalyst. A conversion of $60 \%$ of double bonds was reached after 3 hours of reaction. However, only one hour was needed to get standard requirements and to avoid the epoxide ring opening side reaction that leads to hydroxyl groups. Besides, it was also observed that the formation of hydroxyl groups increases the kinematic viscosity of the biodiesel, being deleterious for the biodiesel properties.

Keywords: EN 14214; ASTM D 6751; Unsaturation degree; lodine value; Cetane number; Linolenic acid methyl ester.

\section{Introduction}

Biodiesel, an alternative diesel fuel, is made from renewable biological sources such as vegetable oils and animal fats. This fuel is biodegradable and non-toxic and has low emission profiles as compared to petroleum diesel (Lapuerta et al., 2008). The properties of biodiesel depend on the fatty acid composition of raw materials because the fatty acid profile of biodiesel is identical to that of the parent oil or fat. In turn, the properties of fatty acid methyl esters (FAME) are determined by the chemical structure of the fatty acids. Molecular weight, degree of unsaturation, branching of the chain, and the presence of chemical functional groups such as hydroxyl and epoxide affect the physical and chemical properties of biodiesel (Wandumesthrige et al., 2009; Ramos et al., 2009; Canakci and Sanli, 2008).

Camelina sativa (L.) Crantz, also known as false flax or gold-of-pleasure, is a broadleaf oilseed flowering plant of the Brassicaceae family (mustard, rapes, canola and crambe) that grows optimally in warm climates. Camelina sativa yields anywhere from 336 to 2,240 kg of seeds per hectare at maturity, with the lipid content of individual seeds ranging between 35 and 45 wt.\% with a protein content within 27 to 32 wt.\%.

The oil from Camelina sativa contains approximately $90 \mathrm{wt} . \%$ of unsaturated fatty acids. This unusual fatty acid pattern is the result of the abundance of C18:1 (12.8 - 14.7\%), C18:2 (16.3 - 17.2 \%), C18:3 $(36.2-39.4 \%)$ and C20:1 (14.0 - $15.5 \%)$ fatty acids. The high C18:3 content is incompatible with EN 14214 specifications and negatively affects biodiesel properties such as the iodine value, the cetane 
number (CN), the oxidation stability index (OSI) and the linolenic acid methyl ester content. Other critical parameters are distillation temperature and the polyunsaturated methyl ester content (PUFA). For these reasons Camelina sativa biodiesel (CSB) presents various problems for motor fuel applications, being necessary to reduce its high degree of unsaturation, and molecular weight.

To improve the properties of biodiesel, various strategies can be carried out: use of additives, winterization, and alteration of the fatty acid composition or genetic modification (Wandumesthrige et al., 2009; Kongyai et al., 2013; Pérez et al., 2010). The addition of additives to biodiesel is probably the simplest method. However, the problem of additive compatibility and the unintended effects on the other fuel properties are of concern. Therefore, the alteration of the fatty ester composition is often preferred and might be better (Kongyai et al., 2013).

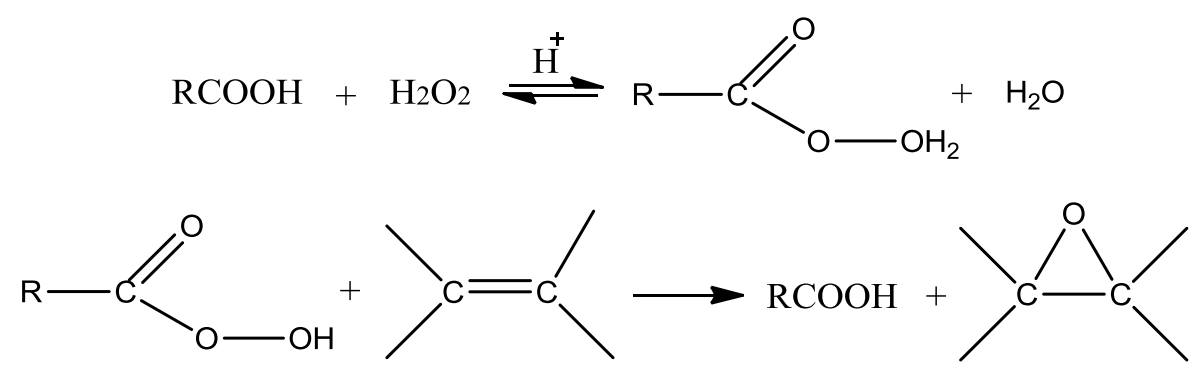

Figure 1. Mechanism of epoxidation reaction

Epoxidation is a reaction of a double bond with active oxygen, which results in the addition of an oxygen atom, converting the original double bond into a three membered epoxide currently named oxirane ring (Figure 1). In general, olefins can be epoxidised with peroxyacids, of which m-chloroperbenzoic acid has been the most often used. Other peroxyacids, especially peracetic and perbenzoic, have also been used (Gamage et al., 2009). Epoxidation of vegetable oils has been extensively studied due to its impact on polymers and resins synthesis. For this reaction, an organic acid like acetic acid, or formic acid, is reacted with hydrogen peroxide to generate peroxyacetic acid as oxygen carrier. These peroxyacids can be used as a separate reagent or can be synthesised in situ, but the most common method is by using a peroxyacid generated in situ due to relative easy and safety manipulation (Gan et al., 1992). In situ epoxidation of vegetable oil with $\mathrm{H}_{2} \mathrm{O}_{2}$ and acetic acid has been previously reported (Vijayagopalan and Gopalakrishnan, 1971; Gamage et al., 2009). It was found that molar ratio of reactants, temperature and catalysts are critical in obtaining acceptable oxirane content. The epoxidation of a vegetable oil must be carried out with great care to prevent any possible side reactions. Figure 2 shows oxirane ring opening reaction that leads to hydroxyl groups.



Figure 2. Oxirane ring opening reaction

Taking into account that Camelina sativa biodiesel does not meet the requirements of EN 14214 and ASTM D 6751 standards, the aim of this work is to enhance the biofuel quality modifying the chemical structure of fatty acid methyl esters by catalytic epoxidation. This treatment has not been described in literature before. To accomplish this goal, the catalytic epoxidation of the Camelina sativa biodiesel was carried out at $60{ }^{\circ} \mathrm{C}$ by using peroxyacetic acid generated in situ and the physical and chemical properties of the modified biodiesel (iodine value, cetane number, oxidation stability and linolenic acid 
methyl ester content, etc.) were compared with those requirements established in the two biodiesel standards (ASTM D6751 and EN 14214).

\section{Material and methods}

\subsection{Materials}

Camelina sativa seeds were ground in Spain. All materials used in the extraction processes; oil characterisation, oil refining process, transesterification process, and characterisation of biodiesel were supplied by Fluka, Panreac, Sigma Aldrich, and Supelco. Reference materials used for biodiesel characterisation were supplied by Conostan, NIST Stanhope-Seta, IIS, IRMM and LGC Standards. Glacial acetic acid (>99.7\%), aqueous hydrogen peroxide (50\%), sulfuric acid (95-97\%), 1-butanol (>99.5\%), hydrogen bromide solution (33\% in acetic acid), Tetrahydrofuran (THF) (>99.9\%) were supplied by Sigma-Aldrich. Diethyl ether (99.7\%), sodium hydroxide (98-100\%), ethanol (96\%), cyclohexane, Wij's reagent, sodium thiosulphate ethanolic solution $(0.1 \mathrm{~N})$ and potassium iodide were supplied by Panreac.

\subsection{Experimental procedure}

The oil was extracted from the seeds by using an oil press KOMET CA $59 \mathrm{G}$, with a feeding capacity of $5-8 \mathrm{~kg} \mathrm{~h}^{-1}$, and an extruder of $0.5 \mathrm{~mm}$. The extraction of the wet cake oil was performed using a Soxhlet apparatus. The oil refining procedure was performed as described by Fernández et al., (2010). The biodiesel was synthesised on a laboratory scale via the conventional homogeneous alkaline catalysed transesterification using a methanol/oil molar ratio of 6:1 and sodium metoxide as catalyst. A molar ratio catalyst/oil of 0.1:1 was used (Casas et al., 2010). The epoxidation of Camelina sativa biodiesel was performed in a jacket borosilicate glass reactor of 1 litre equipped with digital control of stirring from 40 to 2,000 revolutions per minute and a thermostatic bath for temperature regulation withing -10 to $100^{\circ} \mathrm{C}$. This reactor is provided with a lid of three necks in which a reflux condenser, a thermocouple with temperature indicator and the head of stirring are located.

In this work, $0.3 \mathrm{~kg}$ of Camelina sativa biodiesel and $0.5 \mathrm{~mol}$ of acetic acid per mol of instauration were added to the reactor, being the temperature fixed at $40{ }^{\circ} \mathrm{C}$ and the agitation at 400 revolutions per minute. Once the desired temperature was reached, the catalyst $\mathrm{H}_{2} \mathrm{SO}_{4}$ ( $2 \%$ by weight of the aqueous phase) was added. Further, the required amount of aqueous $\mathrm{H}_{2} \mathrm{O}_{2}$ at $50 \%$ by weight (two moles per mol of insaturation) was added drop-wise during half an hour. The reaction was performed at a fixed temperature of $60{ }^{\circ} \mathrm{C}$ under an agitation of 900 revolutions per minute, and a nitrogen atmosphere during 4 hours, considering the completion of $\mathrm{H}_{2} \mathrm{O}_{2}$ addition as the initial time. For characterization purposes, samples were taken out at 30,60,120 and 180 minutes. In the purification of the samples, diethyl ether was used as solvent to separate the organic phase from the aqueous phase in a separating funnel. The residual acetic acid and sulfuric acid in the organic sample were removed by ion exchange in a fix bed column filled with the strongly basic anionic exchange resin Amberlite IRA 402.

\subsection{Analytical methods}

The characterisation methods, analysis techniques and quality controls for the feedstock and the biodiesel were adopted from Carrero and Pérez, (2012). To assess the quality of the oil used in the production of biodiesel, the methods listed in the AOCS Analytical Guidelines Ck 1-07 were used. The biodiesel parameters were tested according to procedures described in the EN 14214 and ASTM D6751 standards. All measurements were carried out in triplicate, and no statistically significant differences were observed among them.

The percentage of oxirane rings was determined by direct method using hydrobromic acid solution in glacial acetic acid according to AOCS Official Method Cd 9-57. The determination of hydroxyl index, in mg KOH per gram of product, was carried out according to AOCS Official Method Tx 1a-66. The presence of functional groups in the biodiesel and the epoxidized biodiesel were confirmed qualitatively by FTIR spectroscopy. 
The $\mathrm{CN}$ has been calculated based on the biodiesel methyl esters composition by using their individual cetane numbers, according to the equation 1 (Knothe, 2005)

$\mathrm{CN}=\sum \mathrm{CN}_{\mathrm{i}} \times \mathrm{w}_{\mathrm{i}}$

where $\mathrm{CN}_{\mathrm{i}}$ is the cetane number for an individual methyl ester, $\mathrm{w}_{\mathrm{i}}$ is the mass fraction of each methyl ester, and $\mathrm{i}$ is a counter.

\section{Results and discussion}

\subsection{Composition of Camelina sativa oil}

The total oil yield from Camelina sativa seeds was 43.9 wt.\%, obtaining a 38.29 wt.\% with the mechanical press and 5.61 wt.\% with the soxhlet extraction. This oil is constituted by saturated (8.63 wt.\%), monounsaturated (32.96 wt.\%), unsaturated of 2 or 3 double bonds (54.10 wt.\%) and polyunsaturated with 4 or more double bonds (2.48 wt.\%) fatty acids, being the linolenic acid (C18:3) the most predominant.

\subsection{Characterisation of Camelina sativa biodiesel}

The transesterification reaction was satisfactorily performed with a yield of 97.5 wt.\% methyl ester content. The separation and purification post-treatments stages were performed properly since the product accomplished with the quality requirements of the EN 14214 standard (glycerol, methanol and metal contents). The properties of Camelina sativa biodiesel (CSB), requirements of the biodiesel standards ASTM D6751 and EN 14214, and the test methods are summarised in Table 1.

Viscosity, cetane number, cloud point, distillation curve and iodine value are directly related to the chemical composition of the CSB. Flash point, methanol content, metal content, sulphur level, acid number, and cold soak filterability are related to the purity of the CSB, the production process, transport and storage (Ciubota-Rosie et al., 2013).

These specifications clearly demonstrate the important relationships between certain properties and highlight the significance of the computed average unsaturation, which is highly correlated with several other properties. Although the ASTM D6751 standard does not limit the iodine value (IV), the EN 14214 standard limits the IV to a maximum of $1.2 \mathrm{~g} \mathrm{I}_{2} \mathrm{~g}^{-1}$. Thus, the iodine value for CSB $\left(1.52-1.53 \mathrm{~g} \mathrm{I}_{2} \mathrm{~g}^{-1}\right)$ is very high and does not satisfy the EN 14214 standards. Engine manufacturers have argued that biodiesel with a high iodine value polymerizes at high temperature, forming deposits on injector nozzles, piston rings and piston ring grooves when these surfaces are heated (Mittelbach and Remschmidt, 2004).

The cetane number (CN) increases with the length chain of the fatty acid and decreases with an increase in the number of double bonds (Ramírez Verduzco et al., 2012). This parameter is very important in the characterization of a biodiesel because it gives a measurement of the combustion quality during ignition. It provides information about the ignition delay of a diesel fuel upon injection into the combustion chamber. Biodiesel with low cetane number tends to cause poor combustion, smoking, and excessive carbon deposits on compression-ignition engine (Srivastava and Prasad, 2000).

CSB has an unsatisfactory oxidation stability of $1.3 \mathrm{~h}$, which is lower than the specified values ASTM D6751 (OSI > $3 \mathrm{~h}$ ) and EN 14214 (OSI > 8 h). Low oxidation stability is commonly found in fuels with a high content of polyunsaturated esters. Methylene groups adjacent to double bonds are particularly susceptible to be attacked by free radicals as the first step of fuel oxidation (Monyem and Van Gerpen, 2001).

According to the above the fatty acids profile (over $90 \mathrm{wt} . \%$ unsaturated fatty acids content) of biodiesel from Camelina sativa does not meet the EN 14214 and ASTM D 6751 requirements and thus, it is necessary its chemical modification, being the epoxidation of CSB proposed for this purpose. 
Table 1. Standard requirements, Camelina sativa biodiesel properties and test methods.

\begin{tabular}{|c|c|c|c|c|c|}
\hline Property & Units & $\begin{array}{c}\text { ASTM } \\
\text { D6751-12 }\end{array}$ & $\begin{array}{c}\text { UNE-EN } \\
14214: 2012 \\
\end{array}$ & CSB & Test Method \\
\hline Density at $15^{\circ} \mathrm{C}$ & $\mathrm{kg} \mathrm{m}^{-3}$ & - & $860-900$ & 888 & EN ISO 12185 \\
\hline Kinematic Viscosity at $40^{\circ} \mathrm{C}$ & $\mathrm{mm}^{2} \mathrm{~s}^{-1}$ & $1.9-6$ & $3.5-5$ & 4.3 & EN ISO 3104 \\
\hline Cold Filter Plugging Point & ${ }^{\circ} \mathrm{C}$ & - & $\begin{array}{l}\text { According to } \\
\text { climate zone }\end{array}$ & -4 & EN 116 \\
\hline Cloud Point & ${ }^{\circ} \mathrm{C}$ & $\begin{array}{l}\text { According } \\
\text { to climate } \\
\text { zone }\end{array}$ & - & 0 & ASTM D 2500 \\
\hline Cetane number & - & $\geq 47$ & $\geq 51$ & 42.76 & EN 15195 \\
\hline Methyl ester content & wt.\% & - & $\geq 96.5$ & 97.5 & EN 14103 \\
\hline $\begin{array}{l}\text { Distillation temperature } \\
\text { AET, } 90 \% \text { recovered }\end{array}$ & ${ }^{\circ} \mathrm{C}$ & $\leq 360$ & - & 369 & ASTM D 1160 \\
\hline$\overline{\text { Flash Point }}$ & ${ }^{\circ} \mathrm{C}$ & $\geq 93$ & $\geq 101$ & 152 & EN ISO 3679 \\
\hline Sulphur content & $\mathrm{mg} \mathrm{kg}^{-1}$ & $\leq 15$ & $\leq 10$ & 0.57 & EN ISO 20846 \\
\hline Carbon residue & wt.\% & $\leq 0.05^{\mathrm{a}}$ & - & $0.019^{\mathrm{a}}$ & EN ISO 10370 \\
\hline Sulphated ash content & wt.\% & $\leq 0.02$ & $\leq 0.02$ & 0.0013 & ISO 3987 \\
\hline Water content & $\mathrm{mg} \mathrm{kg}^{-1}$ & - & $\leq 500$ & 120 & EN ISO 12937 \\
\hline Total contamination & $\mathrm{mg} \mathrm{kg}^{-1}$ & - & $\leq 24$ & 7.3 & EN 12662 \\
\hline $\begin{array}{l}\text { Copper strip corrosion } \\
\left(3 \mathrm{~h}, 50^{\circ} \mathrm{C}\right)\end{array}$ & classification & 3 & 1 & $1 \mathrm{~A}$ & EN ISO 2160 \\
\hline Oxidation stability, $110^{\circ} \mathrm{C}$ & hours & $\geq 3$ & $\geq 8$ & 1.3 & EN 14112 \\
\hline Acid value & $\mathrm{mg} \mathrm{KOH} \mathrm{g}^{-1}$ & $\leq 0.5$ & $\leq 0.5$ & 0.15 & EN 14104 \\
\hline lodine value & $\mathrm{g} \mathrm{I}_{2} \mathrm{~g}^{-1}$ & - & $\leq 1.2$ & 1.52 & EN 14111 \\
\hline Cold Soak Filterability Test & seconds & $\leq 360$ & - & 246 & ASTM D 7501 \\
\hline Linolenic acid methyl ester & wt.\% & - & $\leq 12.0$ & 34.2 & EN 14103 \\
\hline $\begin{array}{l}\text { Polyunsaturated } \\
\text { ( } \geq 4 \text { double bonds) } \\
\text { methyl esters }\end{array}$ & wt.\% & - & $\leq 1$ & 2.08 & EN 15779 \\
\hline
\end{tabular}

\begin{tabular}{|c|c|c|c|c|c|}
\hline Methanol content & wt.\% & $\begin{array}{c}\leq 0.2 \text { or } \\
\text { flash point } \geq \\
130{ }^{\circ} \mathrm{C}\end{array}$ & $\leq 0.2$ & 0.0121 & EN 14110 \\
\hline Monoglyceride content & wt.\% & 0.4 & $\leq 0.7$ & 0.579 & EN 14105 \\
\hline Diglyceride content & wt.\% & - & $\leq 0.2$ & 0.171 & EN 14105 \\
\hline Triglyceride content & wt.\% & - & $\leq 0.2$ & 0.107 & EN 14105 \\
\hline Free glycerol & wt.\% & $\leq 0.02$ & $\leq 0.02$ & 0.006 & EN 14105 \\
\hline Total glycerol & wt.\% & $\leq 0.240$ & $\leq 0.25$ & 0.189 & EN 14105 \\
\hline $\begin{array}{l}\text { Group I metals ( } \mathrm{Na}+\mathrm{K}) \\
\text { Group II metals ( } \mathrm{Ca}+\mathrm{Mg} \text { ) }\end{array}$ & $\mathrm{mg} \mathrm{kg}^{-1}$ & $\begin{array}{l}\leq 5.0 \\
\leq 5.0\end{array}$ & $\begin{array}{l}\leq 5.0 \\
\leq 5.0\end{array}$ & $\begin{array}{l}0.11 \\
0.16\end{array}$ & EN 14538 \\
\hline Phosphorus content & $\mathrm{mg} \mathrm{kg}^{-1}$ & $\leq 10$ & $\leq 4.0$ & $<0.1$ & EN 14107 \\
\hline Water \& Sediment & $\%$ volume & $<0.2$ & - & 0 & ASTM D 2709 \\
\hline
\end{tabular}

${ }^{\mathrm{a}}$ (on $100 \%$ sample)

\subsection{Epoxidation of Camelina sativa biodiesel}

Figure 3 shows the trends for different FAMEs as function of the reaction time. As it was expected, the epoxidation reaction decreases the unsaturation degree. Table 2 shows the properties of epoxidised Camelina sativa biodiesel (ECSB) with the reaction time.

The total unsaturated FAME decreased more than $40 \%$ after one hour of epoxidation reaction. Obviously, the main contribution to this decrease was due to the abatement of the C18:2 and C18:3 
compounds, attending to the highest original contents in the CSB. In the same way, a conversion of PUFA closed to $50 \mathrm{wt} . \%$ was obtained.

These results confirm that after one hour of the epoxidation reaction, ECSB satisfy the standard limits: lodine value $\leq 120 \mathrm{~g} \mathrm{I}_{2} / 100 \mathrm{~g}$, C18:3 $\leq 12 \mathrm{wt} . \%$, PUFA $\leq 1 \mathrm{wt} . \%$, kinematic viscosity values within 1.9-6 ASTM / 3.5-5 EN mm²/s and cetane number $\geq 47 \mathrm{ASTM} / 51 \mathrm{EN}$.

Table 2. Properties of epoxidised Camelina sativa biodiesel with reaction time

\begin{tabular}{lccccc}
\hline Property & CSB & ECSB & ECSB & ECSB & ECSB \\
& & 30 min & 60 min & 120 min & 180 min \\
\hline C14:0 (wt.\%) & 0.05 & 0.1 & 0.1 & 1.4 & 4.6 \\
\hline $\mathrm{C} 15: 0$ (wt.\%) & 0 & 0 & 0.3 & 1.2 & 4.2 \\
\hline $\mathrm{C} 16: 0$ (wt.\%) & 5.2 & 5.6 & 6.2 & 8.3 & 15.8 \\
\hline $\mathrm{C} 18: 0$ (wt.\%) & 2.7 & 2.9 & 3.2 & 4.3 & 8.1 \\
\hline $\mathrm{C} 18: 1$ (wt.\%) & 15.2 & 13.2 & 10.6 & 9.1 & 12.4 \\
\hline $\mathrm{C} 18: 2$ (wt.\%) & 17.9 & 15.9 & 11.2 & 7.9 & 0 \\
\hline $\mathrm{C} 18: 3$ (wt.\%) & 34.2 & 24.7 & 12.0 & 8.1 & 7.8 \\
\hline $\mathrm{C} 20: 0$ (wt.\%) & 1.4 & 1.5 & 1.7 & 2.3 & 4.4 \\
\hline $\mathrm{C} 20: 1$ (wt.\%) & 15.1 & 13.3 & 10.8 & 9.4 & 13.0 \\
\hline $\mathrm{C} 20: 2$ (wt.\%) & 2.2 & 1.8 & 1.3 & 0.9 & 1.3 \\
\hline $\mathrm{C} 20: 4$ (wt.\%) & 1.5 & 1.0 & 0.5 & 0.4 & 0 \\
\hline $\mathrm{C} 22: 0$ (wt.\%) & 0.3 & 0.3 & 0.3 & 0.5 & 0.9 \\
\hline $\mathrm{C} 22: 1$ (wt.\%) & 2.6 & 2.3 & 1.9 & 1.7 & 2.6 \\
\hline $\mathrm{C} 22: 6$ (wt.\%) & 0.62 & 0.6 & 0.5 & 0.5 & 0 \\
\hline Oxidation Stability, $110^{\circ} \mathrm{C}(\mathrm{h})$ & 1.30 & 1.66 & 2.25 & 2.71 & 2.93 \\
\hline lodine Value $\left(\mathrm{g} \mathrm{I}_{2} \mathrm{~g}^{-1}\right)$ & 1.52 & 1.30 & 1.027 & 0.721 & 0.614 \\
\hline PUFA (wt.\%) & 2.08 & 1.6 & 1.0 & 0.9 & 0.0 \\
\hline Kinematic Viscosity, $40^{\circ} \mathrm{C}\left(\mathrm{mm}^{2} \mathrm{~s}^{-1}\right)$ & 4.3 & 4.5 & 6.0 & 12.9 & 42.2 \\
\hline Cetane Number & 45.8 & 48.8 & 52.7 & 55.1 & 60.9 \\
\hline Cloud Point $\left({ }^{\circ} \mathrm{C}\right)$ & 0 & +1 & +2 & +7.3 & +11 \\
\hline & & & & & \\
\hline
\end{tabular}

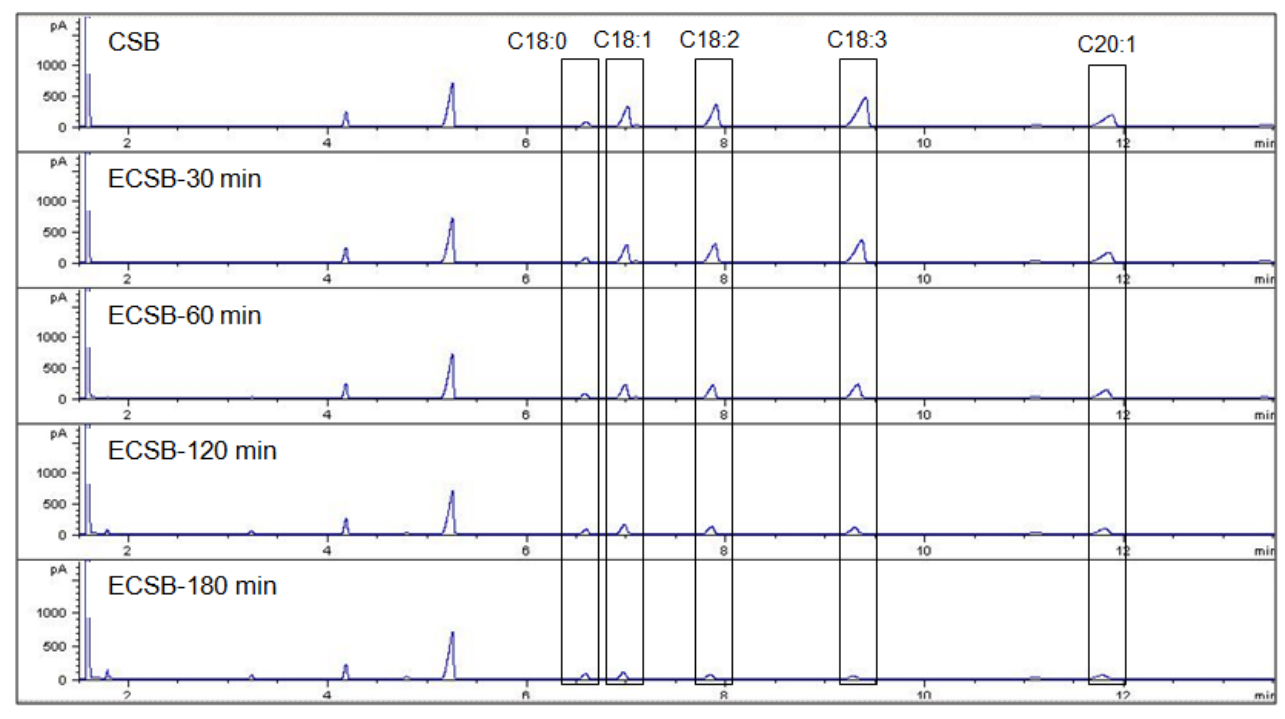

Figure 3. Chromatograms of CSB and ECSB

The epoxidation reaction causes the substitution of the unsaturations by the epoxy group, resulting in the decrease of unsaturated fatty acid content. Besides, the presence of different functional groups unsaturated, epoxidized and hydroxyl-methyl esters may facilitate a closer packing arrangement, promoting the side-by-side parallel packing of the molecules, which would also result in an increase in 
both cloud and flash points and also on the oxidation stability of epoxided biodiesel (Kongyai et al., 2013).

As can be seen in Figure 4, a 60\% of the unsaturated methyl esthers C18:1, C18:2, C18:3 and C20:1 was converted to oxirane rings and hydroxyl groups after $180 \mathrm{~min}$ under the epoxidation reaction. This figure shows that the secondary reaction -epoxide ring opening with water to form hydroxyl groups- takes place in this process. Besides, it is also observed that this reaction is turned into the main one for long time. These hydroxyl groups undergo a deleterious effect on epoxidized biodiesel (ECSB) which is critical because enlarge the viscosity (more than a $45 \%$ ).

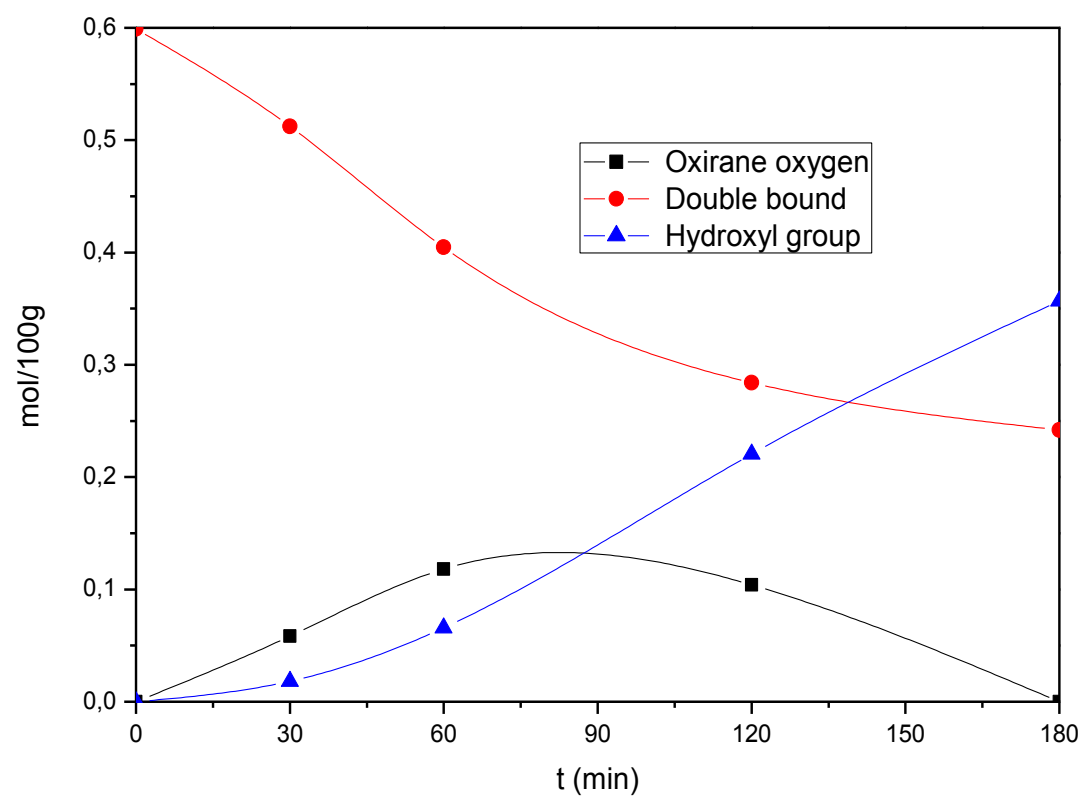

Figure 4. Variation of oxirane oxygen, double bonds and hydroxyl groups

The presence of functional groups in the biodiesel and the epoxidized biodiesel were confirmed qualitatively by FTIR spectroscopy as shown in Figure 5. Double bonds can be observed at the stretching bands 1656 and $3010 \mathrm{~cm}^{-1}$, - $\mathrm{OH}$ groups present a strong stretching band at $3465 \mathrm{~cm}^{-1}$ and the characteristic doublet at $824-842 \mathrm{~cm}^{-1}$ represents the stretch of the oxirane ring.

This figure confirms that the higher the reaction time the lower the concentration of double bonds, the increase hydroxyl groups with time and how oxirane rings disappear for 180 min of reaction.

Finally, in order to achieve a higher conversion of double bonds to oxirane rings the secondary reaction must be avoided and suitable conditions must be researched.

\section{Conclusions}

The high content of unsaturated fatty acids of Camelina sativa biodiesel did not satisfy the requirements of EN 14214 and ASTM D 6751 standards. The epoxidation reaction allowed reaching a conversion of 60 $\%$ of double bonds after 3 hours of epoxidation reaction, modifying its properties. One hour of epoxidation was enough to transform the unstandarised biodiesel in an epoxidised biodiesel that satisfy the established limits for iodine value, C18:3, cetane number, PUFA and viscosity. Long reaction times cannot useful for this purpose because biodiesel viscosity increased sharply with the hydroxyl group content. 


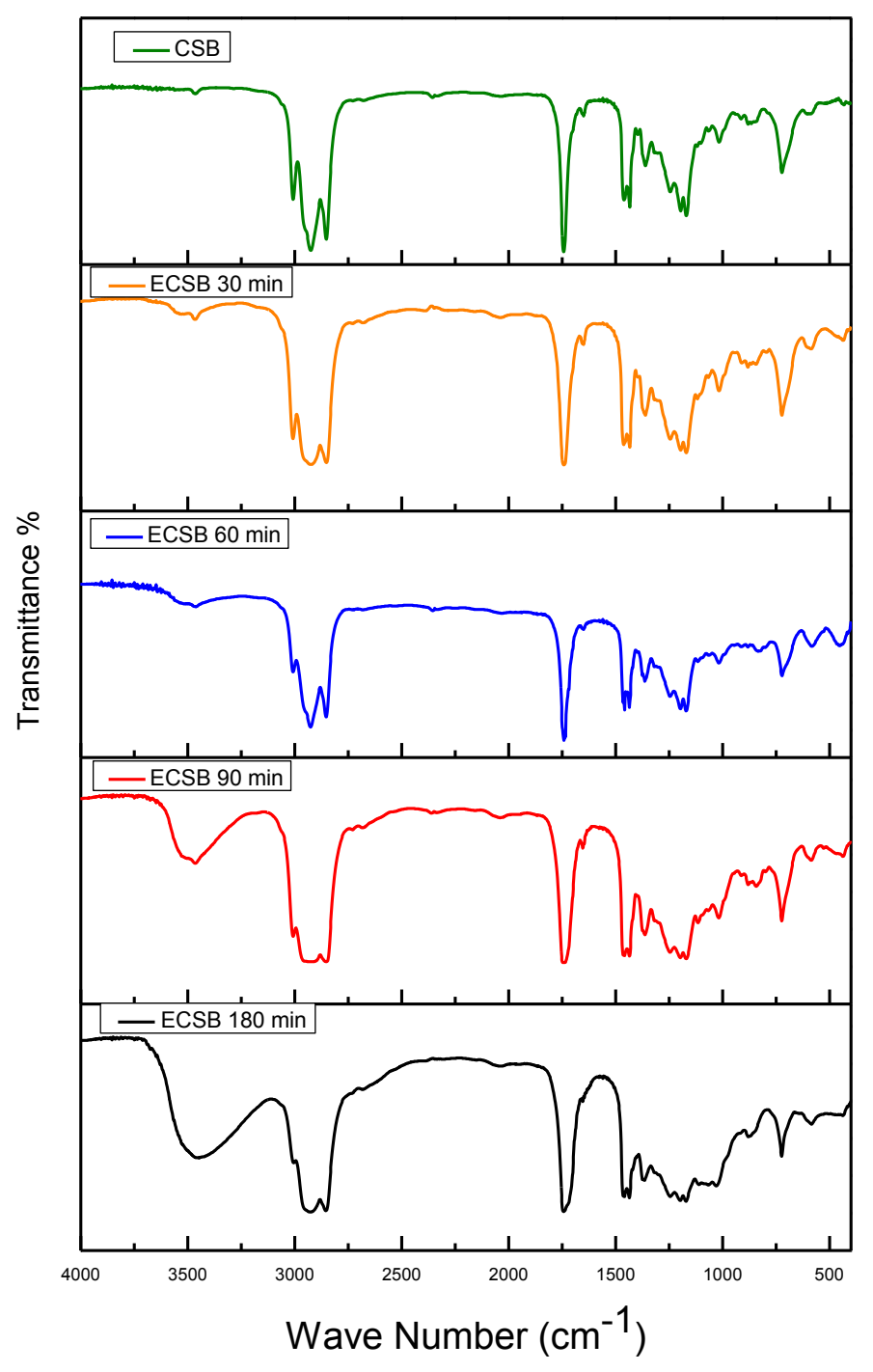

Figure 5. Comparation of FT-IR spectra of CSB and ECSB

\section{Acknowledgments}

Financial support from Junta de Comunidades de Castilla-La Mancha (Project PII1109-0254-0742 and FSE 2007/2013) is gratefully acknowledged.

\section{References}

Canakci M. and Sanli H. (2008), Biodiesel production from various feedstocks and their effects on the fuel properties, Journal of Industrial Microbiological and Biotechnology, 35, 431-441.

Carrero A. and Perez A. (2012), Advances in biodiesel quality control, characterisation and standards developement, in: Advances in biodiesel production Processes and technologies, Luque R. and Melero J.A. (Eds.), Woodhead Publishing, UK.

Casas A., Ruiz J., Ramos M. and Pérez Á. (2010), Effects of Triacetin on Biodiesel Quality, Energy Fuels, 24, 4481-4489.

Ciubota-Rosie C., Ruiz J.R., Ramos M.J. and Pérez Á. (2013), Biodiesel from Camelina sativa: A comprehensive characterisation, Fuel, 105, 572-577.

Fernández C.M., Ramos M., Pérez Á. and Rodríguez J. (2010), Production of biodiesel from winery waste: Extraction, refining and transesterification of grape seed oil. Bioresource Technology, 101, 7019-7024. 
Gamage P.K., O’Brien M. and Karunanayake L. (2009), Epoxidation of some vegetable oils and their hydrolysed products with peroxyformic acid - optimised to industrial scale, Journal of the National Science Foundation of Sri Lanka, 37, 229-240.

Gan L., Goh S. and Ooi K. (1992), Kinetic studies of epoxidation and oxirane cleavage of palm olein methyl esters, Journal of the American Oil Chemists' Society, 69, 347-351.

Knothe G. (2005), Dependence of biodiesel fuel properties on the structure of fatty acid alkyl esters, Fuel Processing Technology, 86, 1059-1070.

Kongyai C., Chalermsinsuwan B. and Hunsom M. (2013), Epoxidation of waste used-oil biodiesel: Effect of reaction factors and its impact on the oxidative stability, Korean Journal Chemical Engineering, 30, 327-336.

Lapuerta M., Armas O. and Rodríguez-Fernández J. (2008), Effect of biodiesel fuels on diesel engine emissions. Progress in Energy and Combustion Science, 34, 198-223.

Mittelbach M. and Remschimidt C. (2004), Biodiesel the comprehensive handbook, Boersedruck Ges. M.B.H., Vienna.

Monyem A. and Van Gerpen J.H. (2001), The effect of biodiesel oxidation on engine performance and emissions, Biomass and Bioenergy, 20, 317-325.

Pérez Á., Casas A., Fernández C., Ramos M. and Rodríguez L. (2010), Winterization of peanut biodiesel to improve the cold flow properties, Bioresource Technology, 101, 7375-7381.

Ramírez Verduzco L., Rodríguez J. and Jaramillo A.(2012), Predicting cetane number, kinematic viscosity, density and higher heating value of biodiesel from its fatty acid methyl ester composition, Fuel, 91, 102-111.

Ramos M., Fernández C., Casas A., Rodríguez L. and Pérez Á. (2009), Influence of fatty acid composition of raw materials on biodiesel properties, Bioresource Technology, 100, 261-268.

Srivastava A. and Prasad R. (2000). Triglycerides-based diesel fuels. Renewable and Sustainable Energy Reviews, 4, 111-133

Vijayagopalan K. and Gopalakrishnan K.S. (1971), Epoxidation of rubber seed oil, Rubber Board Bulletin, 11, 52-54.

Wandumesthrige K., Salley S.O. and Ng S.K.Y. (2009), Effects of partial hydrogenation, epoxidation, and hydroxylation on the fuel properties of fatty acid methyl esters, Fuel Processing Technology, 90, 1292-1299. 